Document downloaded from:

http://hdl.handle.net/10251/150047

This paper must be cited as:

Pal, P.; Kolodziej, C.; Choi, S.; Som, S.; Broatch, A.; Gómez-Soriano, J.; Wu, Y.... (2018). Development of a Virtual CFR Engine Model for Knocking Combustion Analysis. SAE International Journal of Engines. 11(6):1069-1082. https://doi.org/10.4271/2018-01-0187

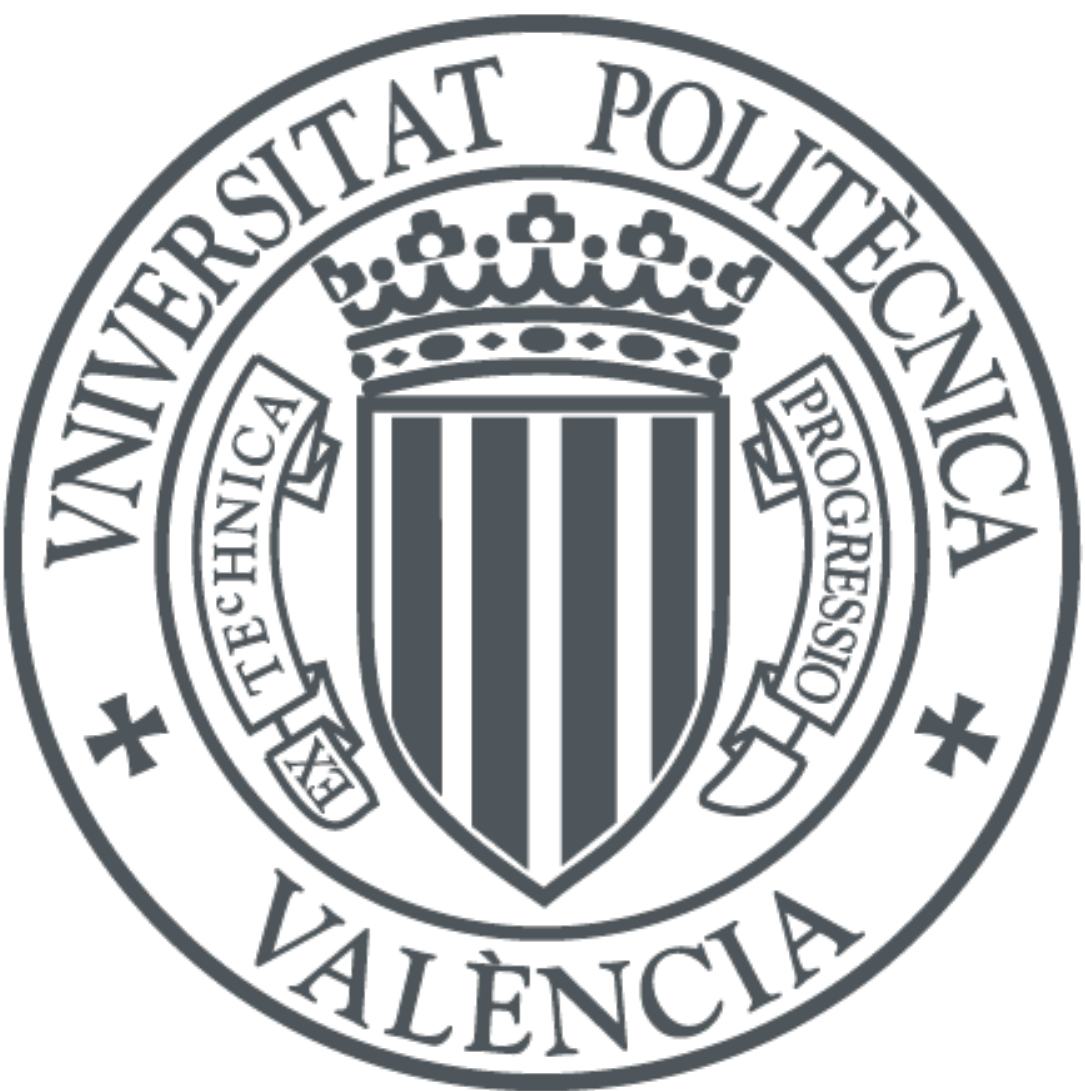

The final publication is available at

https://doi.org/10.4271/2018-01-0187

Copyright SAE International

Additional Information 


\title{
Development of a Virtual CFR Engine Model for Knocking Combustion Analysis
}

\author{
Author, co-author (Do NOT enter this information. It will be pulled from participant tab in \\ MyTechZone) \\ Affiliation (Do NOT enter this information. It will be pulled from participant tab in MyTechZone)
}

\begin{abstract}
Knock is a major bottleneck to achieving higher thermal efficiency in spark-ignited (SI) engines. The overall tendency to knock is highly dependent on fuel anti-knock quality as well as engine operating conditions. It is, therefore, critical to gain a better understanding of fuel-engine interactions in order to develop robust knock mitigation strategies.
\end{abstract}

In the present work, a numerical model based on three-dimensional (3-D) computational fluid dynamics (CFD) was developed to capture knock in a Cooperative Fuel Research (CFR) engine. For combustion modeling, a hybrid approach incorporating the G-equation model to track turbulent flame propagation, and a homogeneous reactor multizone model to predict end-gas auto-ignition ahead of the flame front and post-flame oxidation in the burned zone, was employed. In addition, a novel methodology was implemented wherein a laminar flame speed lookup table generated a priori from a chemical kinetic mechanism could be used to provide flame speed as an input to the G-equation model, instead of using conventional empirical correlations. Multi-cycle Reynolds-Averaged Navier Stokes (RANS) simulations were performed for two different spark timings (STs) corresponding to non-knocking and knocking conditions, with other operating conditions kept the same as those of a standard Research Octane Number (RON) test. Iso-octane was considered as the fuel for the numerical study. Two different reduced kinetic mechanisms were employed to describe end-gas auto-ignition chemistry and to generate the flame speed lookup table. Experimental data, including intake/exhaust boundary conditions, was provided by a spark timing sweep study conducted in an in-house CFR engine. Moreover, cylinder wall/valve/port surface temperatures and residual gas fraction (RGF) were estimated using a well-calibrated onedimensional (1-D) model. On the other hand, a novel methodology was also developed to analyze experimental data for the knocking case and identify the most representative cycle. For the non-knocking case, a good agreement was found between experiment and CFD simulation, with respect to cycle-averaged values of $10 \%$ burn point (CA10), 50\% burn point (CA50) and peak pressure magnitude/location. The virtual CFR engine model was also demonstrated to be capable of predicting average knock characteristics for the knocking case, such as knock point, knock intensity and energy of resonance, with good accuracy.

\section{Introduction}

Transportation plays a major role in modern global economy and accounts for around $20 \%$ of the total energy consumed [1]. By 2040 , the global demand for transport energy is projected to rise by around $40 \%$. Moreover, it is expected that internal combustion (IC) engines will continue to be the mainstream of the world's transportation fleet in the foreseeable future $[2,3]$. However, in recent years, energy and environmental issues have garnered a lot of attention worldwide. In order to curtail greenhouse gas exhaust, especially $\mathrm{CO}_{2}$ emissions, a series of emission standards on vehicle fuel consumption have been mandated in many countries [4]. To be able to continue to meet these stringent regulations on emissions and fuel economy, the efficiency of IC engines needs to be improved.

Currently, there are around 1.1 billion passenger cars in the world, out of which about $85 \%$ are powered by gasoline SI engines. The daily global demand for gasoline is 4.7 billion litres, which accounts for about $40 \%$ of the global transport energy demand [5]. Reducing engine displacement (downsizing) while maintaining the torque output by operating at high loads (boosting) is considered an effective strategy to enhance power density and reduce fuel consumption of SI engines. However, higher loads also result in more severe in-cylinder thermodynamic conditions, promoting the likelihood of abnormal combustion phenomena such as knock.

Knock refers to the ringing noise that occurs as a result of premature auto-ignition of a portion of the end-gas (unburnt) mixture, ahead of the propagating flame front. This causes extremely rapid heat release and high-frequency pressure oscillations, which are highly detrimental to engine durability. Knocking combustion imposes stringent constraints on the performance and efficiency of SI engines by prohibiting the use of more advanced spark timings, higher compression ratios and higher boost pressures [6].

Fuel anti-knock quality is one of the most important parameters that governs the occurrence of knock in SI engines. A fuel's resistance to knock is quantified by its octane number $(\mathrm{ON})$. ONs are measured under two different engine operating conditions in a highly calibrated CFR engine, and are defined as RON and Motor Octane Number (MON). Primary reference fuels (PRFs) provide the scale for both $\mathrm{RON}$ and $\mathrm{MON}$, with iso-octane assigned $\mathrm{RON}=\mathrm{MON}=100$ and $\mathrm{n}$ heptane assigned $\mathrm{RON}=\mathrm{MON}=0$, by definition. A test fuel's RON (or MON) is determined by inducing "standard knock intensity", and then finding a PRF blend that matches the test fuel's knocking behavior. The ON of the test fuel is defined as the volume percentage of iso-octane in that particular PRF blend [7, 8]. MON test is performed at higher engine speed, lower intake air temperature and more advanced spark timing, relative to the RON test, as shown in Table 1. RON of a practical gasoline fuel is, in general, greater than its MON, and the difference between the two is defined as the fuel octane sensitivity $(\mathrm{S}=\mathrm{RON}-\mathrm{MON})$. By convention, for paraffinic PRF blends, $S=0$. For other fuels in general, $S>0$, which is mainly attributed to significantly less pronounced negative temperature coefficient (NTC) behavior exhibited by gasoline as compared to PRFs, which makes them less resistant to auto-ignition under MON

Page 1 of 12 
conditions [1, 9-11]. However, it must be noted that although a fuel's knock propensity is typically associated with the fuel chemistry, recent studies have shown that other properties, such as heat of vaporization (HoV) [12] and thermodynamic compressibility [13] can also contribute to it.

\section{Table 1. RON and MON test conditions.}

\begin{tabular}{|c|c|c|}
\hline Parameter & RON test & MON test \\
\hline Engine speed & $600 \mathrm{rpm}$ & $900 \mathrm{rpm}$ \\
\hline Inlet air temperature & $52^{\circ} \mathrm{C}$ & $38^{\circ} \mathrm{C}$ \\
\hline Inlet mixture temperature & Not controlled & $149^{\circ} \mathrm{C}$ \\
\hline Spark timing & $-13^{0} \mathrm{BTDC}$ & $19^{0}-26^{\circ} \mathrm{BTDC}$ \\
\hline
\end{tabular}

On the other hand, engine operating conditions also play an important role with regard to knock, by interacting with fuel properties. In this context, Kalghatgi $[1,14]$ introduced the Octane Index, OI = RON $\mathrm{K} * \mathrm{~S}$, as a more appropriate metric to quantify the anti-knock quality of fuels by accounting for in-cylinder conditions. Here, $\mathrm{K}$ is an empirical constant representative of the pressure-temperature history of the end-gas mixture. By definition, $\mathrm{K}=0$ at the RON condition and $\mathrm{K}=1$ at the MON condition. It has been shown $[15,16,17]$ that modern downsized boosted SI engines operate at negative $\mathrm{K}$ values (i.e., "beyond RON" conditions), so that a fuel with higher S would be more resistant to knock and enable higher efficiency. This has motivated further studies to investigate potential octane boosters that can be blended with gasoline to increase both RON and S $[18,19]$.

A better understanding of the interaction between fuel properties and engine operating conditions is, therefore, needed to prevent knock and extend the high load limit of SI engines. Furthermore, in-cylinder turbulence and thermal inhomogeneities can also influence the occurrence of knock by way of inducing different auto-ignition regimes in the end-gas [20-26]. The implications of these aspects have not been studied in much detail. In this context, computational fluid dynamics (CFD) can complement engine experiments and serve as a valuable tool to provide more insights into knocking combustion. Successful prediction of knock requires accurate modeling of turbulent flame propagation as well as end-gas auto-ignition. One of the most commonly used knock modeling approaches employs the Gequation combustion model [27] to track the propagating turbulent flame front, and a homogeneous reactor model [28] with detailed/reduced chemical kinetic mechanisms to capture autoignition in the end-gas and post-flame chemistry in the burned zone. However, in previous applications of this approach [29, 30, 31], the fuel laminar flame speed, an input to the G-equation model, was computed using empirical correlations $[32,33]$, which are available for only a few simple fuels, such as iso-octane. Moreover, these correlations are valid for a limited pressure-temperature range only. Therefore, the study of more complex multi-component fuels or fuel blends over a wide range of engine operating conditions becomes difficult with this model. In order to circumvent this limitation, Pal et al. [34] introduced a more general tabulation technique in which a lookup table for laminar flame speed was generated a priori using a chemical kinetic mechanism and subsequently employed to provide flame speeds to the G-equation model. This approach alleviates the need for any empirical correlations and enables the G-equation model to be readily applied to any fuel of interest.

In this work, a 3-D CFD model of CFR engine was developed. For combustion modeling, the methodology developed by the authors [34] as discussed above, was employed. Numerical simulations were performed for both non-knocking and knocking conditions, with iso-

Page 2 of 12 octane as fuel. Realistic intake/exhaust boundary conditions were prescribed based on in-house CFR engine experiments. Cylinder wall/port/valve surface temperatures and residual gas fraction were estimated by a 1-D GT-Power model. The 3-D simulation results were compared against available experimental data to assess the capability of the virtual CFR engine model to predict average combustion characteristics of both normal SI and knocking conditions. Furthermore, a novel methodology was also proposed to identify the most representative cycle from the experimental data of the knocking case. It must be noted that this is the first modeling study of knock in a CFR engine incorporating realistic engine geometry (to the best of the authors' knowledge). A numerical model for CFR engine can have wide applications, ranging from investigating fuel property impact on knock propensity to studying fuel-engine interactions under a wide range of operating conditions.

The remainder of the paper is organized as follows. First, a brief description of the CFR engine experiments and 1-D model is provided. Then, details of the CFD numerical setup, combustion model and chemical kinetic mechanisms are presented in the following sections. Subsequently, results from the numerical simulations are discussed and validated against experimental data. Finally, the paper concludes with a summary of the main findings and future directions.

\section{Methodology}

\section{CFR Engine Experiments}

The standardized single-cylinder CFR F1/F2 engine is used to measure RON and MON of motor fuels based on specific ASTM protocols [7, 8]. Table 2 shows the main specifications of the inhouse Waukesha CFR engine at Argonne National Laboratory. A typical CFR engine setup provides basically two measurements: carburetor sight glass fuel level and knockmeter knock units (KU), giving a relative air-fuel ratio and a relative measure of combustion knock, respectively. Therefore, in order to get more detailed and absolute measurements of engine operating conditions and combustion behavior, several instrumentation upgrades were added to the CFR engine, without affecting engine geometry or performance during standard octane testing. For example, in order to measure absolute air-fuel ratio (lambda), a wide-band lambda sensor was installed in the standard ASTM exhaust line between the exhaust port and the exhaust surge tank. High-speed pressure transducers were employed to obtain crank-angle-resolved intake/exhaust port pressure data. Cycle-averaged intake and exhaust temperatures were measured by K-type thermocouples. In addition, crank-angle-resolved local incylinder pressure measurements were made by an AVL spark plug pressure transducer. More detailed information on the engine controls and instrumentation upgrades can be found in Ref. [35].

The standard RON test condition [7] comprises engine speed of 600 $\mathrm{rpm}$, intake air temperature $\sim 52{ }^{\circ} \mathrm{C}$ and spark timing of -13 crank angle degrees (CAD) after top dead center (ATDC). Experiments were performed at these conditions for iso-octane fuel, except that the ST was varied from -14 CAD ATDC to +6 CAD ATDC, in increments of $1 \mathrm{CAD}$. At each spark timing, useful information was recorded pertaining to engine operating conditions and combustion characteristics using the instrumentation described above. The airfuel ratio was kept fixed at 0.89 , which was determined to be the peak knocking lambda for iso-octane based on a prior lambda sweep test. The compression ratio was fixed at 7.55 , for which standard knock intensity (equivalent to $\sim 50 \mathrm{KU}$ ) was achieved under RON test condition. The knock units were measured by the standard CFR D-1 Detonation Pickup installed in the cylinder head and the Model

Page 2 of 12 
501-C Detonation Meter signal-conditioning unit. Moreover, the knock overpressure (ringing) was measured with the spark plug pressure transducer and calculated using the standard AVL algorithm stored in AVL IndiCom.

Table 2. CFR F1/F2 engine specifications.

\begin{tabular}{|c|c|}
\hline Combustion chamber & Cast iron, flat "pancake" \\
\hline Compression ratio (-) & Adjustable, 4:1 - 18:1 \\
\hline Bore x Stroke (mm) & 82.55 x 114.3 \\
\hline Connecting rod (mm) & 254 \\
\hline Intake valve & $180^{\circ}$ shroud, no rotation \\
\hline Exhaust valve & No shroud, rotating \\
\hline Valve overlap & Positive 5 CAD \\
\hline Fuel system & Carbureted \\
\hline Ignition & Capacitive discharge coil to spark \\
\hline
\end{tabular}

Figure 1 shows some typical characterization of the knocking behavior for the spark timing sweep. Evidently, the level of knock decreased as the spark timing was retarded, with the standard RON spark timing (-13 CAD ATDC) corresponding to $50 \mathrm{KU}$. It is interesting to note that knock was not detectable by the standard CFR knockmeter for spark timings later than -8 CAD ATDC. However, the cylinder pressure transducer still detected slight knock at these operating points. Eventually, by 5 CAD ATDC spark timing, no knock was discerned even by the cylinder pressure transducer. In order to validate the virtual CFR engine model, data for two spark timings were chosen: 5 CAD ATDC (non-knocking combustion) and -13 CAD ATDC (standard RON knock intensity).

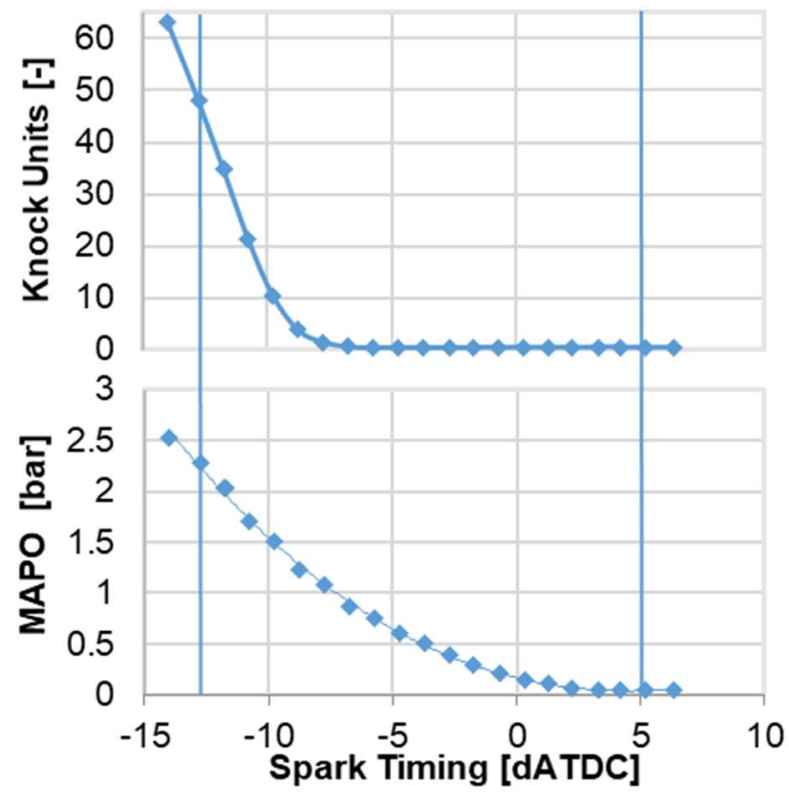

Figure 1. Effect of spark timing retard on CFR knockmeter reading and knock overpressure (expressed in terms of maximum amplitude of pressure oscillations (MAPO))

Page 3 of 12

\section{1-D Engine Model}

A one-dimensional gas dynamics and thermodynamics code, GTPower by Gamma Technologies [36], was used to estimate various initial and boundary conditions for the 3-D CFD simulations. The model was developed based on the three pressure analysis (TPA) method, which uses measured high-speed intake and exhaust pressure data as boundary inputs and calculates fuel burn rate from the measured cylinder pressure. This approach requires minimum engine components with valves and ports, and minimizes uncertainties in intake/exhaust systems and combustion model, allowing more accurate estimation of in-cylinder conditions. However, the TPA method is limited to non-predictive simulations where experimental data is available.
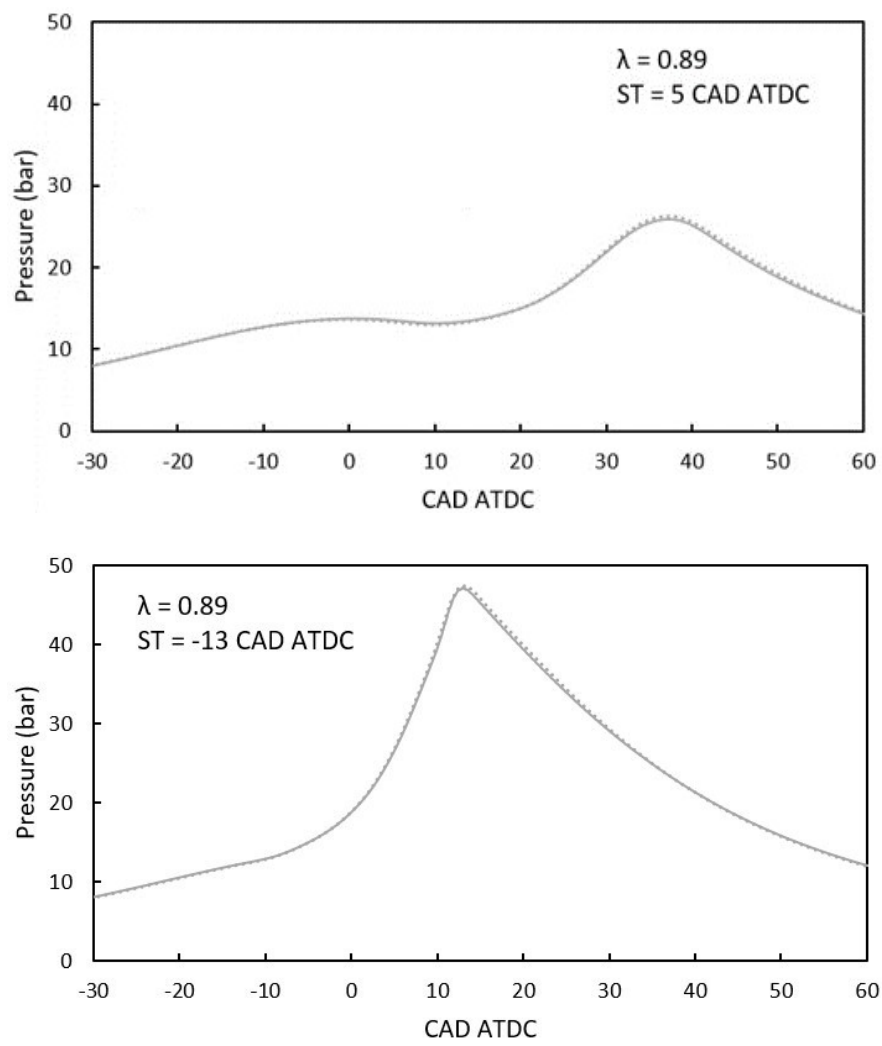

Figure 2. Cycle-averaged cylinder pressure from experiments (solid lines) and 1-D simulations (dotted lines) for spark timings at 5 CAD ATDC (top) and 13 CAD ATDC (bottom).

Table 3. Estimated cylinder wall/valve/port surface temperatures, and IVC conditions from 1-D simulations.

\begin{tabular}{|c|c|c|}
\hline \multirow{2}{*}{$\begin{array}{c}\text { Boundary/Initial } \\
\text { condition }\end{array}$} & \multicolumn{2}{|c|}{ Spark timing } \\
\cline { 2 - 3 } & $\mathbf{- 1 3}{ }^{\mathbf{0}} \mathbf{A T D C}$ & $\mathbf{5}^{\mathbf{0}} \mathbf{A T D C}$ \\
\hline $\mathrm{T}$ _Liner [K] & 430.1 & 426.8 \\
\hline T_Head [K] & 525.2 & 493.2 \\
\hline T_Piston [K] & 485.2 & 461.8 \\
\hline T_InPort [K] & 387.8 & 382.9 \\
\hline T_ExPort [K] & 436.4 & 441.6 \\
\hline T_InValve [K] & 464.9 & 440.4 \\
\hline T_ExValve [K] & 519.6 & 501.9 \\
\hline T ${ }_{\text {IVC }}\left[{ }^{\circ} \mathrm{C}\right]$ & 136.9 & 132.9 \\
\hline Trapped mass [g] & 0.6280 & 0.6329 \\
\hline RGF [\%] & 6.044 & 5.781 \\
\hline
\end{tabular}


To ensure high accuracy of the heat transfer model, cylinder wall and valve/port surface temperatures were computed using the Cylinder Wall Temperature Solver and the Finite Element Cylinder Structure Geometry modules in GT-Power [36]. The engine geometry required by the model was obtained from a 3-D X-ray scan of the engine liner and head. The model was matched against the measured pressure data and the simulated average pressure traces showed good agreement with experiments for the two spark timings chosen, as depicted in Figure 2. The boundary wall temperatures and in-cylinder conditions at intake valve closure (IVC), thereby obtained from the 1-D model are listed in Table 3. A complete description of the 1-D model can be found in Ref. [37].

\section{Virtual CFR Engine Model}

\section{Numerical Model Setup}

A commercial 3-D CFD code, CONVERGE (version 2.3) [38], was used to develop the numerical model and perform full-cycle simulations of the CFR engine. Computational domain representing the engine geometry is shown in Figure 3. The surface mesh was generated from an X-ray scan of the engine cylinder/head assembly, incorporating realistic key geometric features such as the $180^{\circ}$ intake valve shroud, knockmeter port cavity and spark plug cavity. CONVERGE uses a modified, cut-cell Cartesian method for grid generation directly during runtime. In addition, it also has the capability to include fixed embedding of cells i.e., increasing the grid resolution with respect to the base grid size a priori and adaptive mesh refinement (AMR) to refine areas where the subgrid field is the largest. In this study, a base grid size of $2 \mathrm{~mm}$ was used outside the cylinder. Inside the cylinder, a grid size of $1 \mathrm{~mm}$ was employed. Two levels of fixed boundary embedding were specified near the cylinder head, piston and wall (cell size of $0.5 \mathrm{~mm}$ ), while four levels of fixed spherical embedding (radius of $0.5 \mathrm{~mm}$ ) were prescribed to resolve the spark kernel and initial flame development (cell size of 0.125 $\mathrm{mm}$ ). Furthermore, AMR of cells down to $0.5 \mathrm{~mm}$ was used inside the cylinder based on velocity and temperature subgrid scales of 1 $\mathrm{m} / \mathrm{s}$ and $2.5 \mathrm{~K}$, respectively. Previous RANS [39, 40, 41] and large eddy simulation (LES) studies [42, 43] have shown that a minimum grid size of $\sim 0.25-0.5 \mathrm{~mm}$ is sufficient for simulating normal SI combustion and knock. The peak cell count in the simulations reached 2 million approximately. Incipient spark kernel was modeled by adding a volumetric source for a passive scalar $\mathrm{G}$ (described in the next subsection) as a sphere of radius $0.33 \mathrm{~mm}$ in the spark gap at spark timing. In-cylinder turbulence was modeled using the RANS based re-normalized group (RNG) $k-\varepsilon$ model [44] with wall functions. The model proposed by Han and Reitz [45] was employed to account for wall heat transfer. A second-order central difference scheme was used for spatial discretization and a first-order implicit scheme was employed for temporal discretization. In order to capture the high-frequency local pressure oscillations induced by knocking, the maximum value of the Mach Courant-Friedrichs-Lewy (Mach CFL) number was set to 2.0 during combustion. However, for nonknocking conditions, a value of 50 was used. The in-cylinder distributions of $\mathrm{OH}$ and $\mathrm{CH}_{2} \mathrm{O}$ [46] species along with the local pressure difference, were used to visualize knock. The combustion model and fuel chemistry mechanisms used for the simulations are described in the next subsections.

\section{Combustion Modeling Approach}

The G-equation model based on the flamelet theory of turbulent premixed combustion [27], was employed to track the turbulent flame front in an Eulerian manner by solving the following transport equation for the favre-averaged mean of the non-reacting passive scalar $G$ [47]:

Page 4 of 12

$$
\frac{\partial \rho \tilde{G}}{\partial t}+\frac{\partial \rho \tilde{u}_{i} \tilde{G}}{\partial x_{i}}=-D_{T} \kappa\left|\frac{\partial \tilde{G}}{\partial x_{i}}\right|+\rho_{u} s_{T}\left|\frac{\partial \tilde{G}}{\partial x_{i}}\right|
$$

where $s_{T}$ is the turbulent flame speed, $\rho_{u}$ is the unburnt density, $D_{T}$ is the turbulent diffusion term and $\kappa$ is the mean flame front curvature.

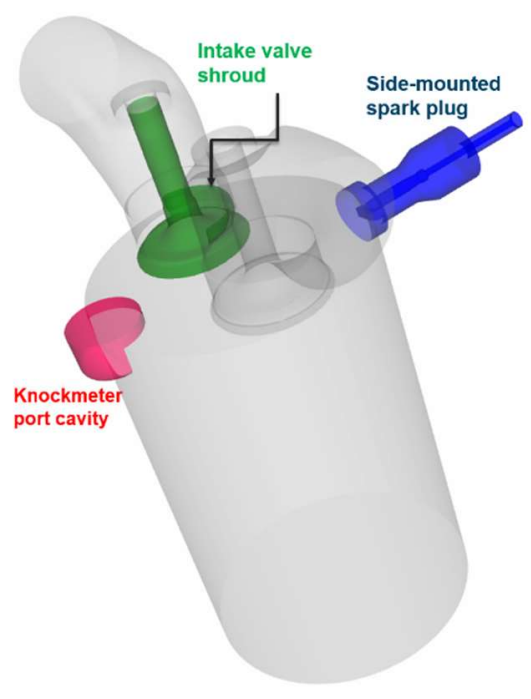

Figure 3. CFR engine geometry (Red: knockmeter port cavity, Green: intake valve with $180^{\circ}$ shroud, Blue: spark plug \& cavity).

The G-equation (also known as "Level set") approach assumes that turbulent premixed combustion occurs in either corrugated flamelet or thin reaction zones regime. By 'tracking', and not 'resolving' a reaction front, the level set method does not suffer from a high resolution requirement for the reaction-diffusion balance in thin fronts [48]. The two terms on the RHS of Eq. (1) are attributed to the influence of curvature and averaged turbulent mass burn rate on the flame front, respectively. The parameter $G$ indicates the distance to the flame front. $G(\boldsymbol{x}, t)=0$ at the mean flame front location. $G<0$ indicates that the region is unburnt, and $G>0$ indicates that the region is burnt. Outside the flame surface, the scalar is required to satisfy:

$$
\left|\frac{\partial \tilde{G}}{\partial x_{i}}\right|=1
$$

In addition, the following expression is used to calculate the turbulent flame speed in the RANS context [27]:

$$
s_{T}=s_{L}+u^{\prime}\left\{-\frac{a_{1}}{2 b_{1}} D a+\left[\left(\frac{a_{1}}{2 b_{1}} D a\right)^{2}+a_{1} D a\right]^{1 / 2}\right\}
$$

where $u^{\prime}$ is turbulent velocity fluctuation, $s_{L}$ is the laminar flame speed, $D a$ is the Damköhler number and $\mathrm{a}_{1}$ and $\mathrm{b}_{1}$ are modeling constants. A value of $b_{1}=4.0$ was used in this work. A more detailed description of the G-equation model can be found in Refs. [27] and [38]. 
The laminar flame speed in Eq. (3) is generally calculated using empirical correlations [32, 33, 41]. However, a major limitation of these correlations is that they are available for only a few fuels, such as iso-octane, ethanol, methanol and their blends. In addition, these correlations are valid for only limited thermodynamic and composition ranges. Therefore, in this work, a more general methodology to incorporate fuel effects was implemented based on tabulated flame speeds [34]. In particular, a lookup table for $S_{L}$ as a function of temperature, pressure, equivalence ratio and residual gas fraction was generated a priori for iso-octane, based on a skeletal kinetic mechanism (discussed in the next subsection), using the CONVERGE 1-D laminar flame speed solver [38]. Interpolation schemes were then implemented in a user-defined function (UDF) to provide appropriate values of $s_{L}$ to Eq. (3) from the lookup table. The ranges of $\mathrm{T} / \mathrm{P} / \Phi / \mathrm{RGF}$ used for generating the lookup table are listed in Table 4. The residual gas was assumed to consist of only the equilibrium products. In total, there were 1071 entries in the lookup table. A sensitivity study with respect to resolution of the flame speed table was also performed. It was found that further reduction of various step sizes (up to $\Delta \mathrm{T}=15 \mathrm{~K}, \Delta \mathrm{P}=2$ bar, $\Delta \mathrm{RGF}=2.5 \%$ ) did not yield any significant differences in the CFD simulation results presented later.

On the other hand, both auto-ignition in the end-gas and post-flame chemistry in the burnt region were captured using the SAGE detailed chemistry solver [28] along with the multi-zone approach, with bins of $5 \mathrm{~K}$ in temperature and 0.05 in equivalence ratio [49]. Although this model does not utilize an explicit turbulent combustion closure $[50,51,52]$, recent studies have shown that it works well if a reasonably refined mesh is employed, as this significantly reduces subgrid effects $[40,53]$.

Table 4. Parameter ranges for laminar flame speed tabulation.

\begin{tabular}{|c|c|c|}
\hline Parameter & Range & Step size \\
\hline Pressure & $1-50$ bar & 3 bar \\
\hline Temperature & $350-1350 \mathrm{~K}$ & $50 \mathrm{~K}$ \\
\hline Fuel-air equivalence ratio & 1.124 (lambda $=0.89)$ & - \\
\hline RGF & $0-20 \%$ & $10 \%$ \\
\hline
\end{tabular}

\section{Fuel Chemistry Effects}

It is critical to capture both flame propagation and end-gas autoignition phenomena to accurately predict knock. For a typical detailed chemistry based approach [46], a single kinetic mechanism has to account for both phenomena. However, the hybrid combustion model described in the previous subsection is more flexible, as it allows for use of two different kinetic mechanisms for end-gas autoignition and flame speed tabulation. This also has some interesting implications from mechanism reduction perspective. A reduced mechanism developed based on the criteria of both ignition delay and flame speed would likely be larger in size as compared to reduced mechanisms developed considering only one of them. Therefore, with the hybrid combustion model, two smaller mechanisms could be employed instead of one larger mechanism. This has the potential to lower the computational expense of CFD simulations, especially for knocking combustion, where the low Mach CFL number already restricts simulation time-step markedly.

In this work, a 48-species PRF mechanism by Liu et al. [54] was chosen to describe end-gas auto-ignition. Figure 4 shows a comparison of homogeneous ignition delay timings predicted by the PRF mechanism with experimental data available from the literature [55-58], for a stoichiometric iso-octane/air mixture. It can be Page 5 of 12 observed that the reduced mechanism predicts experimental data very well and is, therefore, well suited for the operating conditions considered in this study. However, the 48-species mechanism overpredicts laminar flame speeds for iso-octane, as is evident from Figure 5. Flame speed results are also shown for a 165-species skeletal mechanism [59], which was developed by the authors from a detailed gasoline surrogate mechanism [56]. It can be clearly observed that the 165 -species mechanism is in much better agreement with experimental data on flame speeds [60-65]. On the other hand, the 48-species mechanism is in much better agreement with experiments, as far as ignition delay is concerned (Figure 4). Based on these comparisons, the 48 -species mechanism was employed in the simulations to describe end-gas auto-ignition chemistry and the 165-species mechanism was used to generate the laminar flame speed lookup table. This combined approach offers higher accuracy than using either of the two mechanisms for both purposes. In addition, this keeps the number of species transport equations solved by the CFD code relatively small (only 48 in this case), thereby resulting in low computational expense.
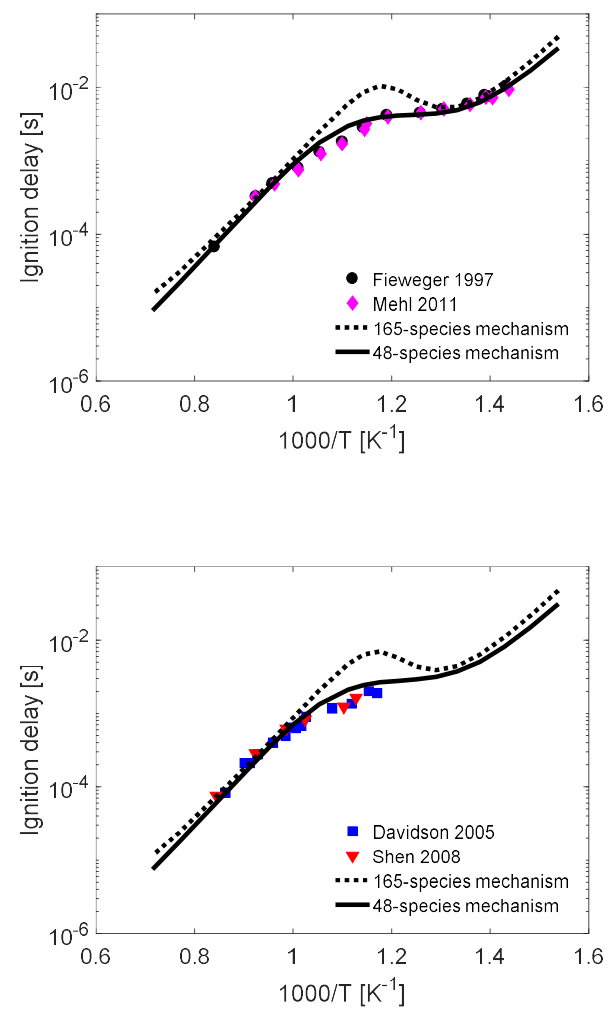

Figure 4. Homogeneous ignition delay of stoichiometric iso-octane/air mixture versus temperature at $40 \mathrm{~atm}$ (top) and $50 \mathrm{~atm}$ (bottom). Symbols denote experimental data [55-58] and lines show numerical results [54, 59].

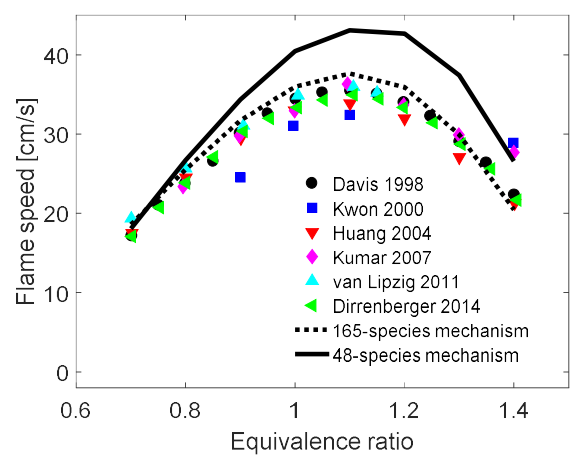




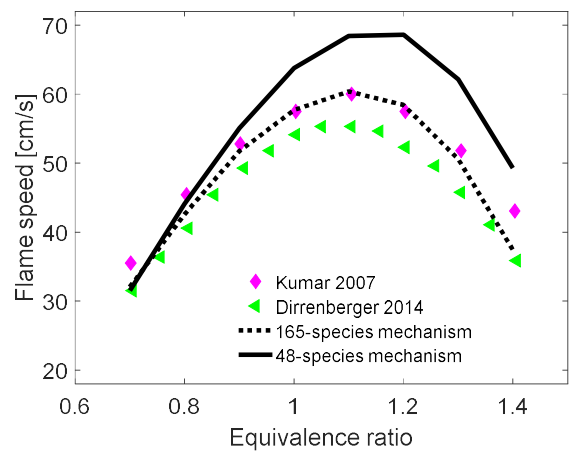

Figure 5. Laminar flame speed of iso-octane/air mixture versus equivalence ratio at $298 \mathrm{~K}$ (top) and $398 \mathrm{~K}$ (bottom). The pressure is $1 \mathrm{~atm}$. Symbols denote experimental data [60-65] and lines show numerical results [54, 59].

\section{Results and Discussion}

Full-cycle unsteady RANS simulations were performed for both the non-knocking (ST of 5 CAD ATDC) and knocking (-13 CAD ATDC) operating points. Six consecutive cycles were simulated for each case, out of which the first cycle was discarded from the analysis to remove any effect of initial conditions. Actual intake and exhaust valve lift profiles measured from the CFR engine were used in the simulations. Cycle-averaged crank-angle-resolved pressures and cycle-averaged temperatures from experiments were prescribed at the intake/exhaust boundaries in the CFD model. Estimated cylinder wall/port/valves surface temperatures and residual gas fraction were provided by the 1-D model (Table 2 ). In order to fairly assess the CFD model performance, the numerical and experimental results were compared for the same location as that of the pressure transducer in experiments.

Each simulation was run using 80 processors on the Peregrine computing cluster at National Renewable Energy Laboratory (NREL). Approximate runtimes of each engine cycle for the nonknocking and knocking cases were 48 hours and 76 hours, respectively. In the next subsections, the numerical results are presented and validated against available experimental data.

\section{Non-knocking Combustion (ST: 5 CAD ATDC)}

Figure 6 (top) shows cylinder pressure traces of the five simulated cycles together with all the 300 cycles from experiment and the cycle-averaged experimental pressure trace, for ST of 5 CAD ATDC. It can be seen that all the numerical pressure traces are well within the experimental spread, except during the early stage of flame development. This slight discrepancy could be attributed to the fact that a detailed spark ignition model was not employed in the simulation. In addition, the spark kernel was assumed to be spherical which might not be representative of the actual shape. Nevertheless, the CFD model is able to capture the average combustion behavior reasonably well, as observed from Figure 6 (bottom) comparing the cycle-averaged experimental and numerical pressure traces. The simulation predicts the cycle-averaged peak cylinder pressure magnitude as well as location very accurately. Moreover, the differences in CA10 and CA50 between experiment and simulation are $5.0 \%$ and $3.0 \%$, respectively.
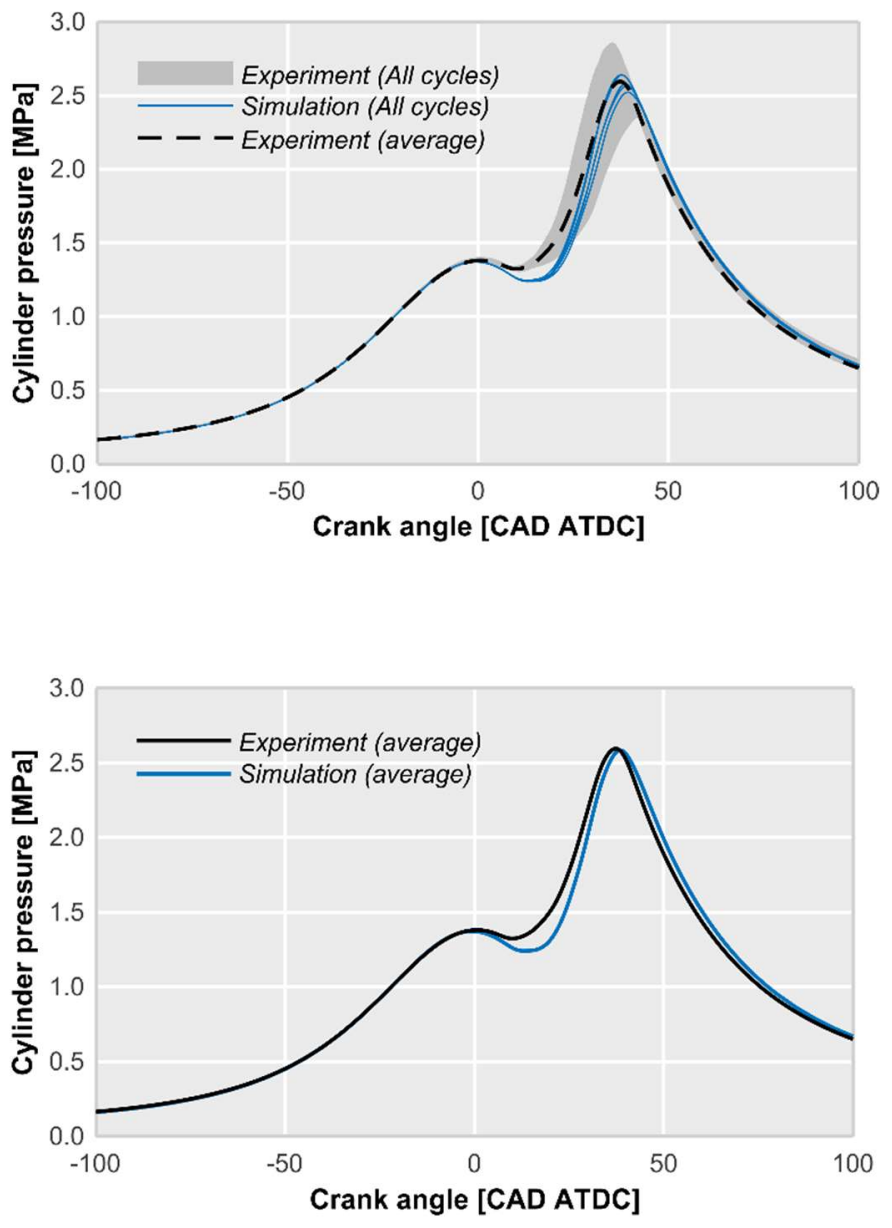

Figure 6. Temporal evolution of in-cylinder pressure for both experiment and simulation (ST: 5 CAD ATDC).

\section{Knocking Combustion (ST: -13 CAD ATDC)}

\section{Experimental Data analysis}

As opposed to non-knocking conditions, simple cycle averaging is not suitable for providing a pressure trace representative of the average combustion characteristics (knock intensity, energy of resonance, etc.) of a knocking case because cycle averaging smoothens out the pressure fluctuations. Therefore, in this study, a novel methodology was developed to identify the most representative cycle of an operating point exhibiting knock. The main principle behind this technique lies in preserving the average characteristics of the high frequency content of the pressure signal.

The selection procedure aimed at first choosing a few cycles which showed least deviation from the average values of three characteristic parameters of knocking combustion. While the maximum pressure rise rate $(d P / d t)_{\max }$ was used to characterize the uniform in-cylinder pressure rise, the unsteady pressure field was described by the energy of resonance $\left(E_{\mathrm{res}}\right)$ [66] and $M A P O$ [67]. Considering these three parameters, a cost function $(C F)$ was defined for each cycle $i$ as follows:

$$
C F_{i}=\frac{\left|(d P / d t)_{\max }^{i}-(d P / d t)_{\max }^{\text {avg }}\right|}{(d P / d t)_{\text {max }}^{\text {avg }}}+\frac{\left|E_{\text {res }}^{i}-E_{\text {res }}^{\text {avg }}\right|}{E_{\text {res }}^{\text {avg }}}+\frac{\left|M A P O_{i}-M A P O_{\text {avg }}\right|}{M A P O_{\text {avg }}}
$$


Cost function was calculated using Eq. (4) for all the experimental cycles and the top four cycles having the lowest cost function values were chosen as potential candidates for the most representative cycle. These four cycles $(24,64,149,169)$ are plotted in Figure 7. In addition, all the experimental cycles, the cycle-averaged pressure trace and standard deviation (SD) band around the cycle-averaged pressure are also depicted. Clearly, cycle 24 lies outside the SD band and therefore, was discarded.

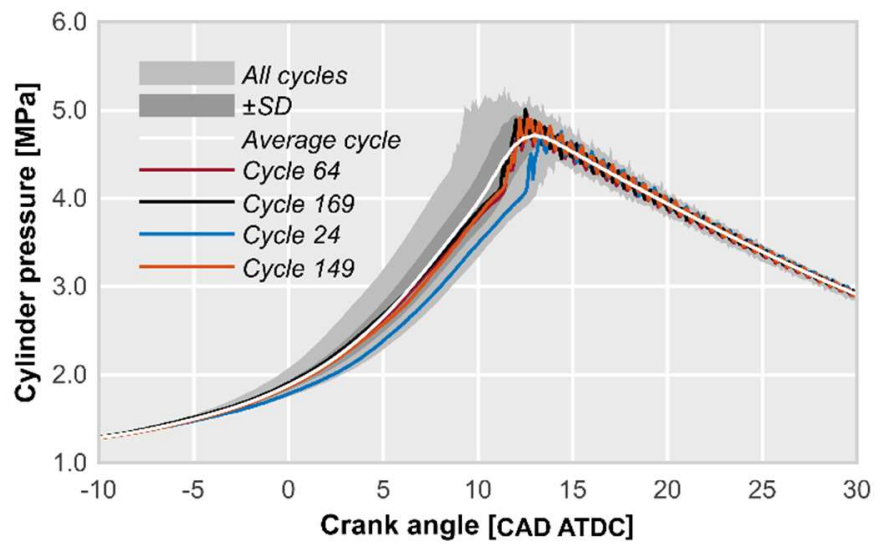

Figure 7. Experimental cycles for the knocking case (ST: -13 CAD ATDC). Candidates for the most representative pressure trace are also highlighted.

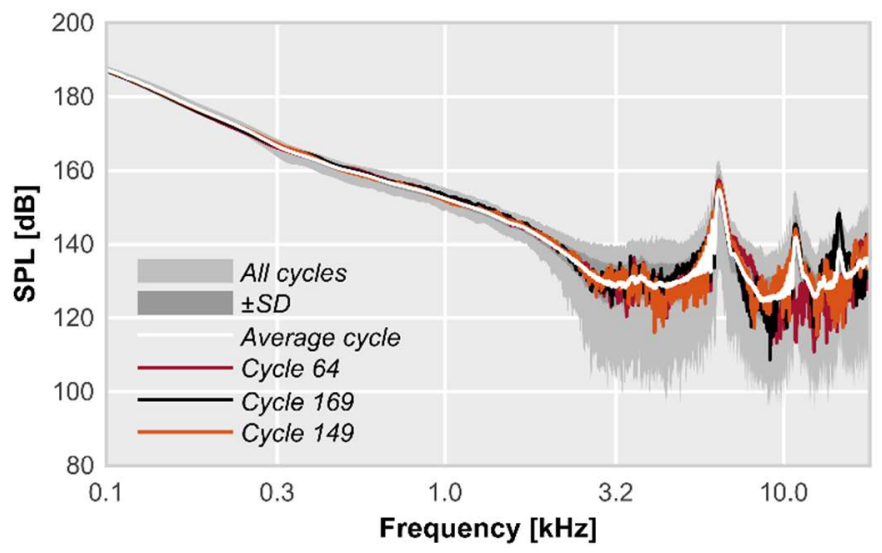

Figure 8. In-cylinder pressure spectra of the experimental cycles (ST: -13 CAD ATDC).

Subsequently, the pressure spectra [66] of the remaining candidate cycles were compared with the average pressure spectra of all cycles as shown in Figure 8. It is evident that only cycle 169 correctly captures the frequency response in the whole broadband, since some of the three resonant peaks observed in the average spectrum are not reproduced in the rest of the candidate cycles. Therefore, cycle 169 was considered to be the most representative pressure trace.

A unique feature of knocking combustion in a CFR engine is the socalled "knock point" [68]. It is the crank angle at which a distinct change occurs in the slope of in-cylinder pressure under knocking conditions. At this crank angle, pressure rise due to auto-ignition dominates that due to flame propagation. In the present work, knock point of each cycle was estimated as the crank angle at which the absolute value of the second derivative of in-cylinder pressure exceeded $2 \mathrm{MPa} / \mathrm{cad}^{2}$. The same criterion was also employed by Foong et el. [69] in their experimental study. Figure 9 shows the knock points of all the experimental cycles (top) and the most representative pressure trace (middle), calculated using this criterion. It is evident that the knock points are predicted with very high accuracy. However, it must be noted that the threshold value for determining the knock point was not obtained analytically. Therefore, it can presumably vary depending on fuel chemistry and operating conditions. It is also interesting to note that the knock point of the most representative cycle (cycle 169) is nearly the same as the average knock point (Figure 9 (bottom)), even though knock point was not used as a parameter in Eq. (4) to determine the most representative cycle.
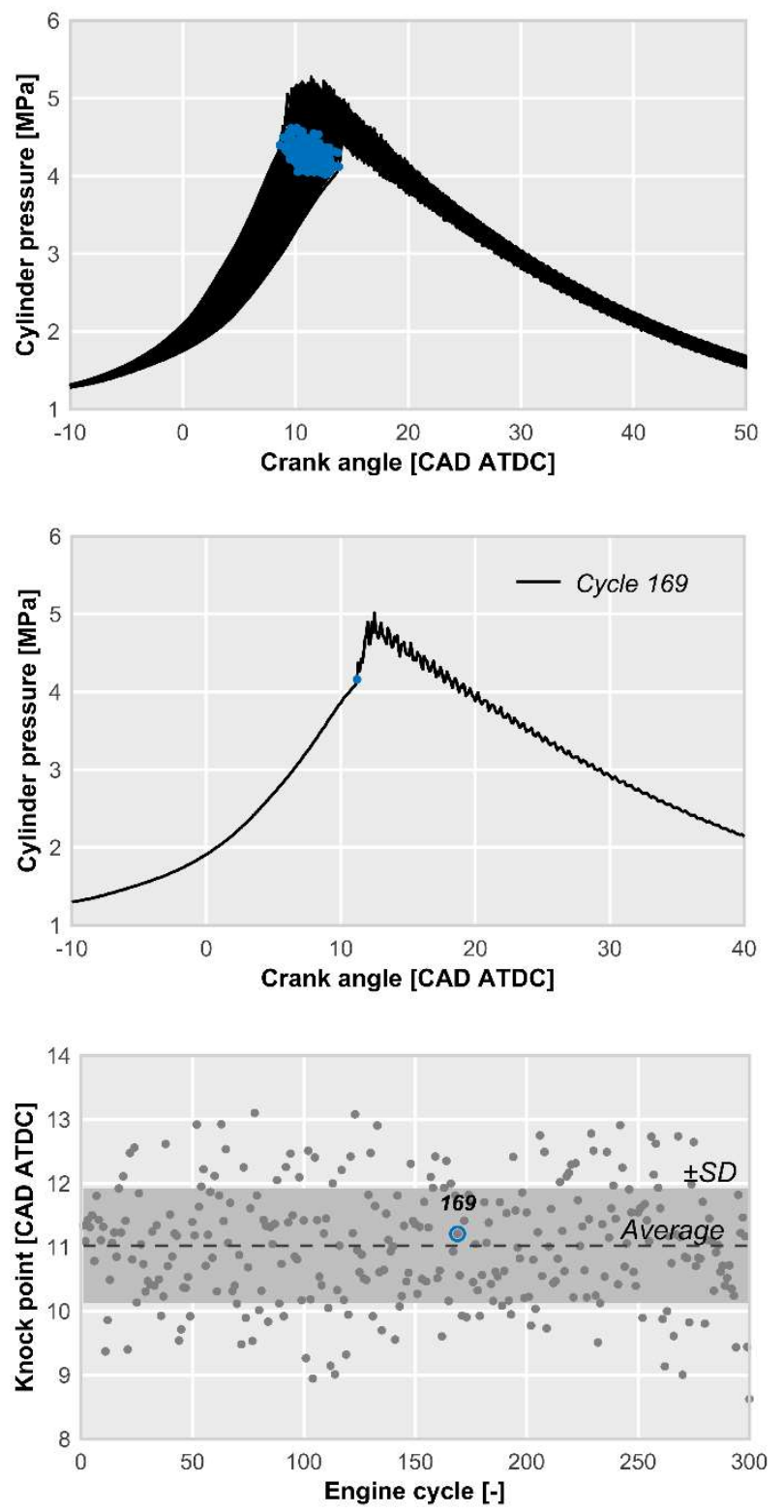

Figure 9. Knock points of the experimental cycles (ST: -13 CAD ATDC).

\section{Validation of Numerical Results}

The numerical results of pressure evolution at the spark plug transducer location are plotted in Figure 10. In addition, all the experimental cycles including the most representative cycle are also shown. Qualitatively, the numerical cycles exhibit a characteristic sudden change in the slope of pressure evolution before the occurrence of pressure oscillations, very similar to the experimental 
cycles. The pressure at knock point is predicted well by the simulation as well. Furthermore, all the numerical cycles are reasonably well bracketed by the experimental spread, similar to the non-knocking case.

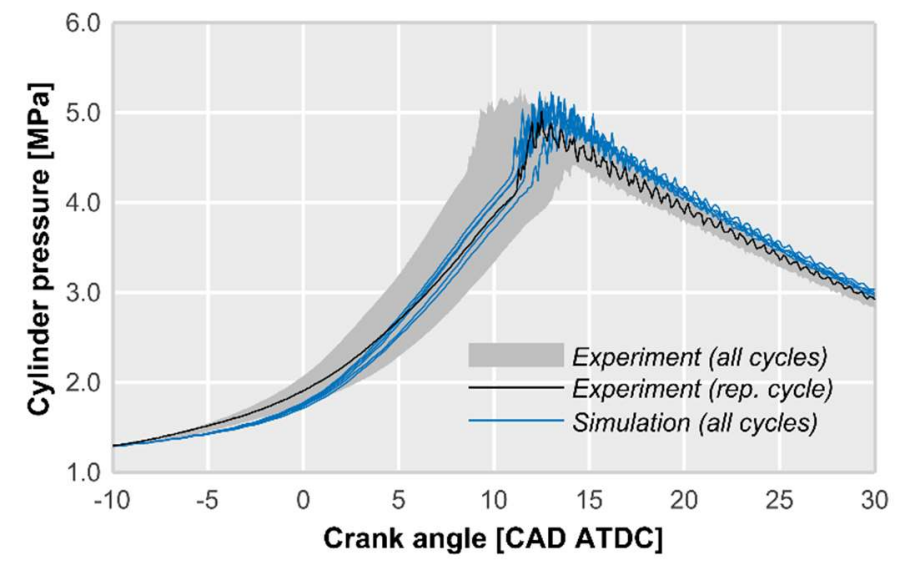

Figure 10. Temporal evolution of in-cylinder pressure for both experiment and simulation (ST: -13 CAD ATDC).

A quantitative comparison of the average knock characteristics between the most representative pressure trace from experiment and simulation results is shown in Table 5. A very good agreement was achieved, with the CFD model predicting slightly higher average knock intensity and average energy of resonance. Moreover, average knock point was predicted quite accurately by simulation with an error of only 0.15 CAD.

Table 5. Average knock characteristics from experiment and simulation.

\begin{tabular}{|c|c|c|}
\hline Knock characteristic & $\begin{array}{c}\text { Experiment (Most } \\
\text { representative cycle) }\end{array}$ & Simulation \\
\hline $\begin{array}{c}\text { Average knock intensity } \\
\text { (MAPO) }\end{array}$ & 2.3 bar & 2.57 bar \\
\hline Average knock point & 11.15 CAD ATDC & $11.30 \mathrm{CAD}$ \\
\hline $\begin{array}{l}\text { Average energy of } \\
\text { resonance }\end{array}$ & $15.86 \mathrm{KPa}^{2} \mathrm{~s}$ & $17.2 \mathrm{KPa}^{2} \mathrm{~s}$ \\
\hline
\end{tabular}

Finally, the evolutions of flame propagation and auto-ignition development in simulation were analyzed to look into the knocking phenomena in more detail. Figure 11 shows the contour plots of $\mathrm{OH}$ and $\mathrm{CH}_{2} \mathrm{O}$ mass fractions, and the local pressure difference, on a horizontal cut plane passing through the spark plug electrode, for the third simulation cycle. Intake and exhaust valves are located on the left and right sides, respectively. Results are shown for four different crank angles. It must be noted that $\mathrm{OH}$ is a very good marker for regions governed by high temperature chemistry, such as the flame front and burned gas behind the flame front. On the other hand, presence of $\mathrm{CH}_{2} \mathrm{O}$ is a prominent indicator of low temperature chemistry. From Figure 11, it can be seen that the turbulent flame gets preferentially pushed towards the intake side, which can be attributed to the effect of swirl generated by the intake valve shroud. At 10.7 CAD ATDC, there is considerable amount of $\mathrm{CH}_{2} \mathrm{O}$ in the end-gas signifying enhanced reactivity. However, the pressure is spatially uniform. Subsequently, at 11.0 CAD ATDC (which is also the estimated knock point for this cycle), part of the end-gas (on the exhaust side) abruptly auto-ignites, indicated by the sudden consumption of $\mathrm{CH}_{2} \mathrm{O}$ and formation of $\mathrm{OH}$. This causes local pressure imbalance leading to the formation of a pressure wave. The pressure wave, then travels from one side of combustion chamber to the other (11.1-11.3 CAD ATDC). These phenomena result in the Page 8 of 12 subsequent in-cylinder pressure fluctuations (ringing) as seen in Figure 10.

\subsection{CAD ATDC}
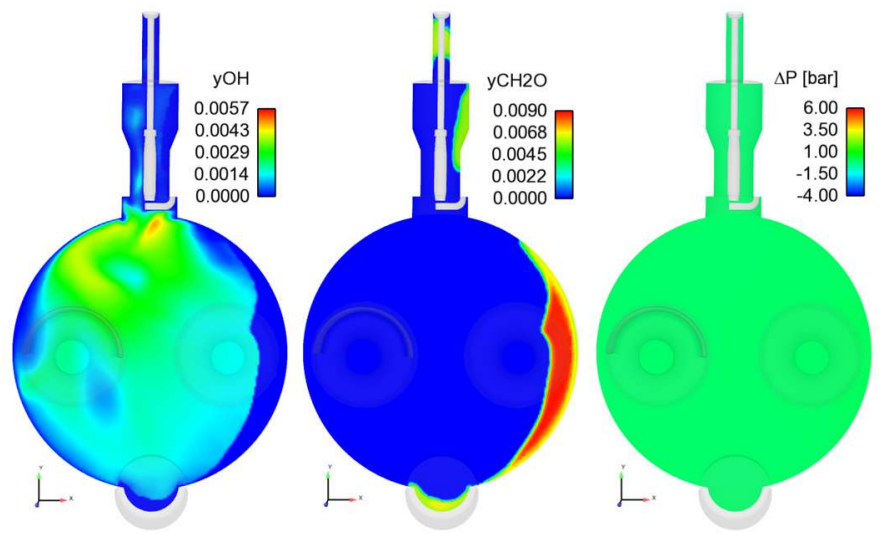

\subsection{CAD ATDC}
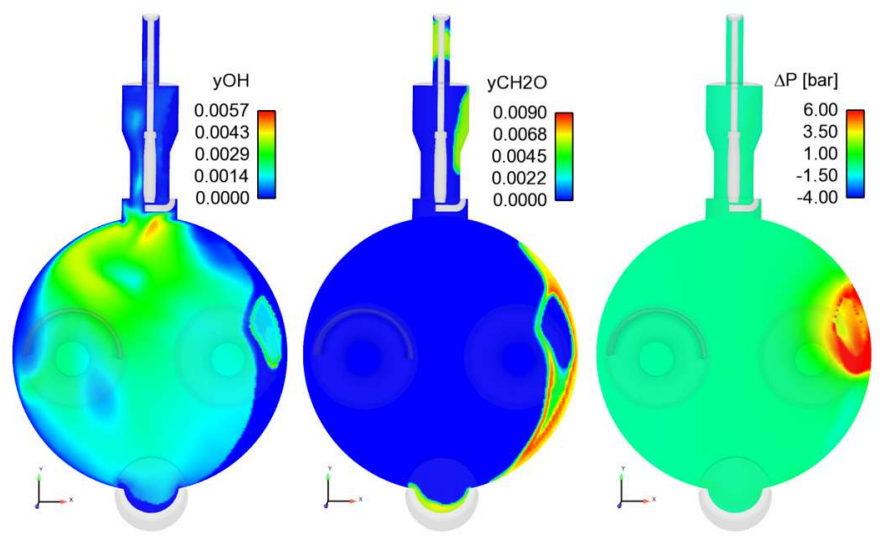

\subsection{CAD ATDC}
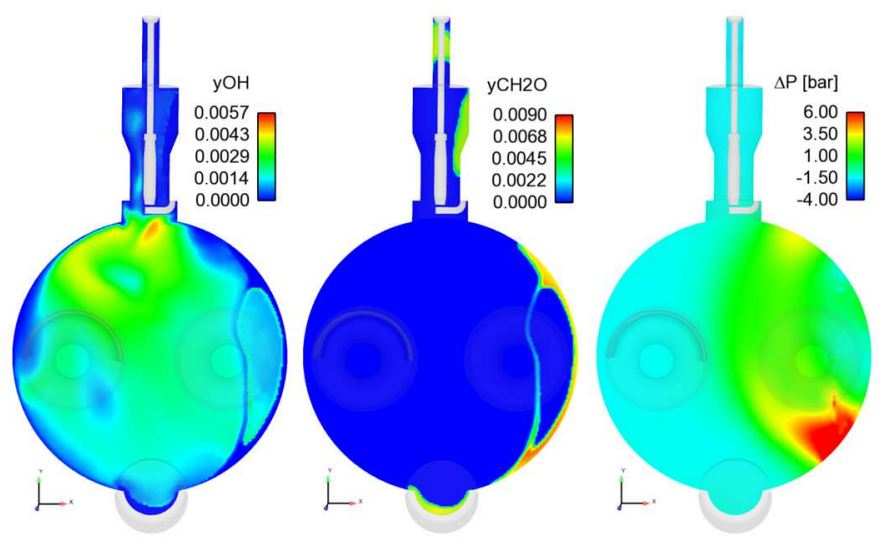


\subsection{CAD ATDC}
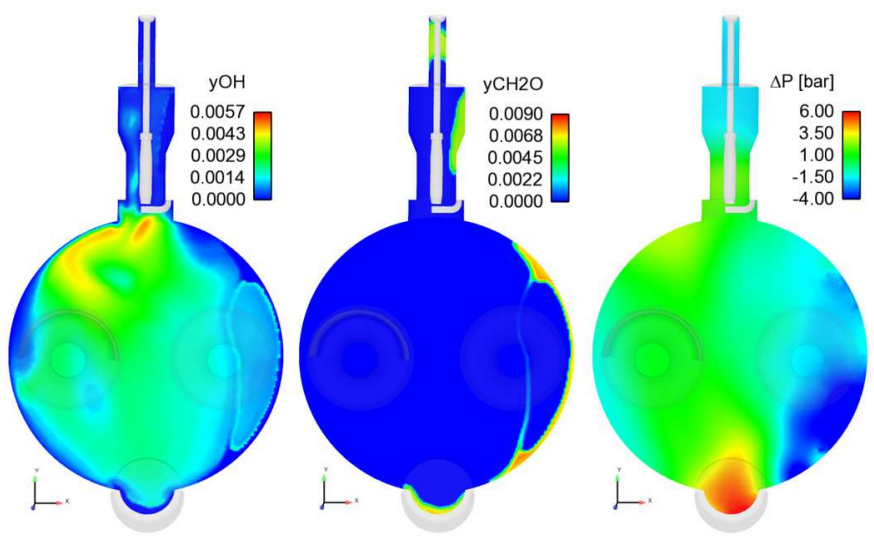

\subsection{CAD ATDC}
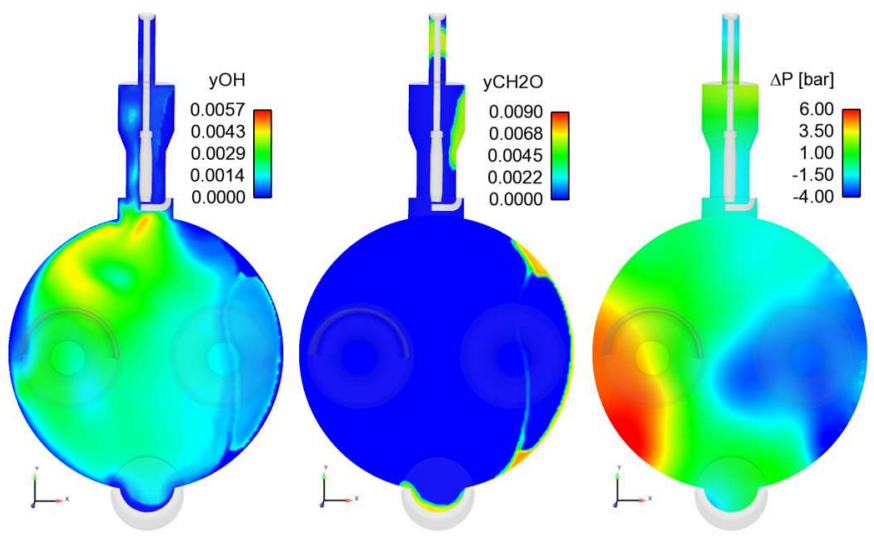

Figure 11. Contour plots of $\mathrm{OH}$ and $\mathrm{CH}_{2} \mathrm{O}$ mass fractions, and local pressure difference on a horizontal cut plane passing through the spark plug electrode, for the third simulation cycle. Intake and exhaust valves are located on the left and right sides, respectively. Knockmeter port cavity can be seen at the bottom.

The main goal of the present numerical study was to assess the capability of virtual CFR engine model to predict combustion characteristics, for both non-knocking and knocking conditions. It is important to note that the proposed methodology of laminar flame speed tabulation using a chemical kinetic mechanism requires the mechanism to be predictive under engine-relevant conditions. This calls for a rigorous validation of kinetic mechanisms against highpressure laminar flame speed measurements to ensure their suitability for engine CFD simulations. Secondly, in this work, a relatively small number of consecutive engine cycles were simulated in the RANS framework. As a result, cycle-to-cycle variability (CCV) was not adequately captured, as evident from Figures 6 and 10. Another point to note is that the combustion behaviors of the two ST cases considered here show no variability from one cycle to another. For ST of 5 CAD ATDC, none of the cycles were knocking and for ST of $-13 \mathrm{CAD}$ ATDC, all the cycles were knocking $\left(M A P O_{i}>1\right.$ bar). Therefore, in future work, multi-cycle LES will be performed to predict $\mathrm{CCV}$ for not only these two extreme cases, but also for intermediate STs, which would fall under the category of "light knock" or "incipient knock". In addition to LES, advanced spark ignition models [70] will be employed to capture the initial spark kernel growth more accurately. As a numerical tool, the virtual CFR engine model can be used to readily test different fuels or fuel blends and investigate the influence of fuel properties on the resultant knocking tendency. Furthermore, parametric tests can also be carried Page 9 of 12 out with the model to gain more insights into fuel-engine interactions at different operating conditions relevant to modern SI engines.

\section{Summary and Conclusions}

In the present work, a multidimensional CFD model was developed to capture knocking combustion in a CFR engine. The combustion modeling strategy entailed a new hybrid approach employing homogeneous reactor multi-zone model to predict end-gas autoignition and G-equation model with tabulated laminar flame speeds to track the turbulent flame propagation. The model was used to simulate both non-knocking (ST of 5 CAD ATDC) and knocking (ST of -13 CAD ATDC) operating points for iso-octane fuel. Multi-cycle RANS simulations were performed for both the cases. The intake/exhaust boundary conditions were provided by in-house CFR engine experiments. On the other hand, cylinder wall/valve/port surface temperatures and residual gas fraction were prescribed by a well-calibrated 1-D model. Based on validation against homogeneous ignition delay and laminar flame speed experimental data from the literature, a 48-species reduced PRF mechanism was chosen to describe auto-ignition chemistry in the end-gas, while the laminar flame speed table was generated using a 165-species skeletal mechanism. For the non-knocking case, simulation predicted the cycle-averaged combustion characteristics, such as peak pressure magnitude/location, CA10 and CA50 reasonably well. With regard to the knocking case, first the experimental data was analyzed using a novel methodology to identify the most representative cycle. The technique was based on the idea of preserving the average characteristic features of knocking combustion: $(d P / d t)_{\max }, E_{\text {res }}$ and $M A P O$. In addition, the knock points of the experimental and numerical cycles were determined based on a threshold value of the second derivative of in-cylinder pressure. The numerical cycles were also shown to be well within the corresponding experimental spread. Thereafter, a comparison between the most representative cycle from experiment and simulation results was carried out. It was found that the model predictions of various average knock characteristics (knock point, MAPO and energy of resonance) were in good agreement with experimental data. Lastly, visualization of the in-cylinder distributions of $\mathrm{OH}$ and $\mathrm{CH}_{2} \mathrm{O}$ species, and local pressure difference showed the occurrence of knock onset near the exhaust valve.

Future studies with the virtual CFR engine model will include multicycle LES to capture knock CCV, testing more complex fuel surrogates/blends, investigating effects of fuel properties on knocking tendency and exploring fuel-engine interactions at boosted conditions relevant to modern SI engines.

\section{References}

1. Kalghatgi, G.T., "Developments in Internal Combustion Engines and Implications for Combustion Science and Future Transport Fuels", Proc. Combust. Inst. 35: 101-115, 2015, doi: 10.1016/j.proci.2014.10.002.

2. Reitz, R., "Directions in Internal Combustion Engine Research", Combust. Flame. 160: 1-8, 2013, doi 10.1016/i.combustflame.2012.11.002.

3. Kalghatgi, G., "The Outlook for Fuels for Internal Combustion Engines", Int. J. Engine Res. 15(4): 383-398, 2014, doi: 10.1177/1468087414526189.

4. Wang, Z., Liu, H., and Reitz, R., "Knocking Combustion in Spark Ignition Engines”, Prog. Energy Combust. Sci. 61: 78112, 2017, doi: $10.1016 /$ j.pecs.2017.03.004.

5. Kalghatgi, G., "Knock Onset, Knock Intensity, Superknock and Preignition in Spark Ignition Engines", Int. J. Engine Res. 1-14, 2017, doi: $10.1177 / 1468087417736430$. 
6. Heywood, J.B., "Internal Combustion Engine Fundamentals", McGraw-Hill, 1988.

7. ASTM D2699-12, "Standard Test Method for Research Octane Number of Spark-Ignition Engine Fuel”, ASTM International, West Conshohocken, PA, 2012.

8. ASTM D2700-16, "Standard Test Method for Motor Octane Number of Spark-Ignition Engine Fuel", ASTM International, West Conshohocken, PA, 2016.

9. Leppart, W., "The Chemical Origin of Fuel Octane sensitivity", SAE Paper No. 902137, 1979, doi: 10.4271/902137.

10. Mehl, M., Faravelli, T., Giavazzi, F., Ranzi, E. et al., "Detailed Chemistry Promotes Understanding of Octane Numbers and Gasoline Sensitivity”, Energy Fuels. 20: 2391-2398, 2006, doi: 10.1021/ef060339s.

11. Westbook, C.K., Mehl, M., Pitz, W.J., and Sjoberg, M., "Chemical Kinetics of Octane Sensitivity in a Spark-Ignition Engine", Combust. Flame. 175: 2-15, 2017, doi: 10.1016/j.combustflame.2016.05.022.

12. Sluder, C.S., Szybist, J.P., McCormick, R.L., Ratcliff, M.A. et al., "Exploring The Relationship Between Octane Sensitivity and Heat-of-Vaporization", SAE Int. J. Fuels Lubr. 9, 2016, doi 10.4271/2016-01-0836.

13. Tao, M., Wu, T., Ge, H., DelVescovo, D. et al., 2017, “A kinetic Modeling Study on Octane Rating and Fuel Sensitivity in Advanced Compression Ignition Engines", Combust. Flame. 185: 234-244, doi: 10.1016/i.combustflame.2017.07.020.

14. Kalghatgi, G.T., "Fuel/Engine Interactions", SAE International, Warrendale, PA, 2013.

15. Kalghatgi, G.T., "Auto-ignition Quality of Practical Fuels and Implications for Fuel Requirements of Future SI and HCCI Engines", SAE Paper No. 2005-01-0239, 2005, doi: 10.4271/2005-01-0239.

16. Kalghatgi, G.T., "Fuel Anti-knock Quality- Part I, Engine Studies", SAE Paper No. 2001-01-3584, 2001, doi: 10.4271/2001-01-3584.

17. Kalghatgi, G.T., "Fuel Anti-knock Quality- Part II, Vehicle Studies- How Relevant is Motor Octane Number (MON) for Modern Engines?", SAE Paper No. 2001-01-3585, 2001, doi: 10.4271/2001-01-3585.

18. Zhang, B., Sarathy, S.M., "Lifecycle Optimized EthanolGasoline Blends for Turbocharged Engines", Appl. Energy. 181: 38-53, 2016, doi: 10.1016/j.apenergy.2016.08.052.

19. Boot, M.D., Tian, M., Hensen, E.J.M., and Sarathy, S.M., "Impact of Fuel Molecular Structure on Auto-ignition BehaviorDesign Rules for Future High Performance Gasolines", Prog. Energy Combust. Sci. 60: 1-25, 2017, doi: 10.1016/j.pecs.2016.12.001.

20. Im, H.G., Pal, P., Wooldridge, M.S., and Mansfield, A.B., "A Regime Diagram for Autoignition of Homogeneous Reactant Mixtures with Turbulent Velocity and Temperature Fluctuations", Combust. Sci. Technol. 187(8): 1263-1275, 2015, doi: $10.1080 / 00102202.2015 .1034355$.

21. Pal, P., Valorani, M., Arias, P.G., Im, H.G. et al., "Computational Characterization of Ignition Regimes in a Syngas/Air Mixture with Temperature Fluctuations", Proc. Combust. Inst. 36: 3705-3716, 2017, doi: 10.1016/j.proci.2016.07.059.

22. Pal, P., Mansfield, A.B., Arias, P.G., Wooldridge, M.S. et al., "A Computational Study of Syngas Auto-ignition Characteristics at High-Pressure and Low-Temperature Conditions with Thermal Inhomogeneities", Combust. Theory Model. 19(5): 587-601, 2015, doi: 10.1080/13647830.2015.1068373.

23. Pal, P., Mansfield, A.B., Wooldridge, M.S., and Im, H.G., "Characteristics of Syngas Auto-ignition at High Pressure and Low Temperature Conditions with Thermal Inhomogeneities",
Energy Procedia. 66:1-4, 2015, doi: $\underline{10.1016 / \text { j.egypro.2015.02.003. }}$.

24. Pal, P., Im, H.G., Wooldridge, M.S., and Mansfield, A.B., "Auto-ignition Phenomena in Thermally Inhomogeneous Turbulent Reacting Flows; Numerical Validation of a Regime Diagram", 10 $0^{\text {th }}$ Asia-Pacific Conference on Combustion, 2015.

25. Pal, P., Valorani, M., Im, H.G., and Wooldridge, M.S., "Prediction of Strong and Weak Ignition Regimes in Turbulent Reacting Flows with Temperature Fluctuations: A Direct Numerical Study", 68 th Annual Meeting of APS Division of Fluid Dynamics, 60 (21), 2015.

26. Pal, P., Im, H.G., Wooldridge, M.S., and Mansfield, A.B., "Effects of Turbulence and Temperature Fluctuations on Syngas Auto-ignition", $7^{\text {th }}$ European Combustion Meeting, ISBN 978963-12-1257-0, 2015.

27. Peters, N., "Turbulent Combustion", Cambridge University Press, Cambridge, UK, 2000.

28. Som, S., Longman, D.E., Luo, Z., Plomer, M et al., "Three Dimensional Simulations of Diesel Sprays Using n-dodecane As a Surrogate", Fall Technical Meeting of the Eastern States Section of the Combust. Inst, 2011.

29. Liang, L. and Reitz, R.D., "Spark Ignition Engine Combustion Modeling Using a Level Set Method With Detailed Chemistry", SAE Paper No. 2006-01-0243, 2006, doi: 10.4271/2006-01$\underline{0243}$.

30. Liang, L., Reitz, R.D., Iyer, C.O., and Yi, J., "Modeling Knock in Spark-Ignition Engines Using a G-equation Combustion Model Incorporating Detailed Chemical Kinetics", SAE Paper No. 2007-01-0165, 2007, doi: 10.4271/2007-01-0165.

31. Wang, Z., Wang, Y., and Reitz, R.D., "Pressure oscillation and chemical kinetics coupling during knock processes in gasoline engine combustion", Energy Fuels. 26(12): 7107-717119, 2012, doi: $10.1021 / \mathrm{ef} 301472 \mathrm{~g}$.

32. Metghalchi, M. and Keck, J.C., "Burning Velocities of Mixtures of Air and Methanol, Isooctane and Indolene at High Pressures and Temperatures", Combust. Flame. 48: 191-210, 1982, doi: $\underline{10.1016 / 0010-2180(82) 90127-4 .}$.

33. Gulder, O.L., "Correlations of Laminar Combustion Data for Alternative S.I. Engine Fuels", SAE Paper No. 841000, 1984, doi: $10.4271 / 841000$.

34. Pal, P., Wu, Y., Lu, T., Som, S. et al., "Multi-dimensional CFD simulations of knocking combustion in a CFR engine", Proceedings of the ASME 2017 Internal Combustion Engine Fall Technical Conference, ICEF2017-3599: V002T06A017, 2017, doi: 10.1115/ICEF2017-3599.

35. Kolodziej, C. and Wallner, T., "Combustion Characteristics of Various Fuels during Research Octane Number Testing on an Instrumented CFR F1/F2 Engine", Combust. Engines. 171(4): 164-169, 2017, doi: 10.19206/CE-2017-427.

36. GT Power v7.5 Documentation, Gamma Technologies, 2014.

37. Choi, S., Kolodziej C., Wallner, T., and Hoth, A., "Development and Validation of a Three Pressure Analysis (TPA) GT-Power Model of the CFR F1/F2 Engine for Estimating Cylinder Conditions", SAE Technical Paper 2018-01-0848, 2018, doi: 10.4271/2018-01-0848.

38. CONVERGE 2.3 Theory Manual, Convergent Science Inc., Middleton, WI, 2016.

39. Givler, S., Raju, M., Pomraning, E., Senecal, P. et al., "Gasoline Combustion Modeling of Direct and Port-Fuel Injected Engines Using a Reduced Chemical Mechanism", SAE Paper No. 201301-1098, 2013, doi: 10.4271/2013-01-1098.

40. Pomraning, E., Richards, K., and Senecal, P., "Modeling Turbulent Combustion Using a RANS Model, Detailed Chemistry, and Adaptive Mesh Refinement", SAE Paper No. 2014-01-1116, 2014, doi: 10.4271/2014-01-1116.

41. Scarcelli, R., Richards, K., Pomraning, E., Senecal, P.K. et al., "Cycle-to-Cycle Variations in Multi-Cycle Engine RANS

Page 10 of 12 
Simulations", SAE Paper No. 2016-01-0593, 2016, doi: 10.4271/2016-01-0593.

42. Robert, A., Richard, S., Colin, O., Martinez, et al., "LES Prediction and Analysis of Knocking Combustion in a Spark Ignition Engine", Proc. Combust. Inst. 35: 2941-2948, 2015, doi: 10.1016/j.proci.2014.05.154.

43. Robert, A., Richard, S., Colin, O., and Poinsot, T., "LES Study of Deflagration to Detonation Mechanisms in a Downsized Spark Ignition Engine", Combust. Flame. 162(7): 2788-2807, 2015, doi: 10.1016/j.combustflame.2015.04.010.

44. Han, Z. and Reitz, R. D., "Turbulence Modeling of Internal Combustion Engines Using RNG k- $\varepsilon$ Models," Combust. Sci. Technol. 106: 267-295, 1995, doi: 10.1080/00102209508907782.

45. Han, Z. and Reitz, R. D., "A Temperature Wall Function Formulation for Variable Density Turbulence Flow with Application to Engine Convective Heat Transfer Modeling," Int. J. Heat Mass Transfer. 40(3): 613-625, 1997, doi: 10.1016/0017-9310(96)00117-2.

46. Pan, J., Wei, H., Shu, G., Pan, M., "LES Analysis of Autoignition Induced Abnormal Combustion Based on a Downsized SI Engine", Appl. Energy. 191: 183-192, 2017, doi: 10.1016/j.apenergy.2017.01.044.

47. Ewald, J. and Peters, N., "A Level Set Based Flamelet Model for the Prediction of Combustion in Spark Ignition Engines", $15^{\text {th }}$ Int. Multidimensional Eng. Model. User Group, Detroit, MI, USA, 2005.

48. Kim, S.H., "A front propagation formulation for under-resolved reaction fronts", Int. J. Comp. Phys. 285: 193-207, 2015, doi: 10.1016/j.jcp.2014-12-051.

49. Babajimopoulos A., Assanis D.N., Flowers D.L., Aceves S.M. et al., "A fully coupled computational fluid dynamics and multizone model with detailed chemical kinetics for the simulation of premixed charge compression ignition engines," Int. J. Engine Res. 6(5): 497-512, 2005, doi: 10.1243/146808705X30503.

50. Pal, P., Keum, S. and Im, H.G., "Assessment of flamelet versus multi-zone combustion modeling approaches for stratifiedcharge compression ignition engines", Int. J. Engine Res. 17(3): 280-290, 2016, doi: 10.1177/1468087415571006.

51. Pal, P., "Computational modeling and analysis of low temperature combustion regimes for advanced engine applications", Ph.D. Dissertation, University of Michigan-Ann Arbor, 2016, http://hdl.handle.net/2027.42/120735.

52. Keum, S., Pal, P., Im, H.G., Babajimopoulos, A. et al., "Effects of fuel injection parameters on the performance of homogeneous charge compression ignition at low-load conditions", Int. J. Engine Res. 17(4): 413-420, 2016, doi: 10.1177/1468087415583597.

53. Pal, P., Probst, D., Pei, Y., Zhang, Y. et al., "Numerical Investigation of a Gasoline-Like Fuel in a Heavy-Duty Compression Ignition Engine Using Global Sensitivity Analysis", SAE Int. J. Fuels Lubr. 10(1), 2017, doi: 10.4271/2017-01-0578.

54. Liu, Y. D., Jia, M., Xie, M. Z., and Pang, B., "Enhancement on a Skeletal Kinetic Model for Primary Reerence Fuel Oxidation by Using Semidecoupling Methodology", Energy Fuels. 26(12): 7069-7083, 2012, doi: 10.1021/ef301242b.

55. Fieweger, K., Blumenthal, R., and Adomeit, G., "Self-Ignition of S.I. Engine Model Fuels: A Shock Tube Investigation at High Pressure", Combust. Flame. 109: 599-619, 1997, doi: 10.1016/S0010-2180(97)00049-7.

56. Mehl, M., Pitz, W.J., Westbrook, C.K., and Curran, H.J., "Kinetic Modeling of Gasoline Surrogate Components and Mixtures Under Engine Conditions", Proc. Combust. Inst. 33: 193-200, 2011, doi: 10.1016/j.proci.2010.15.027.

57. Davidson, D., Gauthier, B., and Hanson, R., "Shock Tube Ignition Measurements of Iso-octane/air and Toluene/air at High
Pressures", Proc. Combust. Inst. 30: 1175-1182, 2005, doi: 10.1016/j.proci.2004.08.004.

58. Shen, H.-P. S., Vanderover, J., and Oehlschlaeger, M.A., "A Shock Tube Study of Iso-octane Ignition at Elevated Pressures: The Influence of Diluent Gases", Combust. Flame. 155: 739755., 2008, doi: 10.1016/j.combustflame.2008.06.001.

59. Wu, Y., Pal, P., Som, S., and Lu, T., "A skeletal Chemical Kinetic Mechanism for Gasoline and Gasoline/Ethanol Blend Surrogates for Engine CFD Applications", Int. Conference Chem. Kinetics, 2017.

60. Davis, S.G. and Law, C.K., "Determination of Fuel Structure Effects on Laminar Flame Speeds of $\mathrm{C}_{1}$ to $\mathrm{C}_{8}$ Hydrocarbons", Combust. Sci. Technol. 140: 427-449, 1998, doi: 10.1080/00102209808915781.

61. Kwon, O.C., Hassan, and M.I., Faeth, G.M., "Flame/Strech Interactions of Premixed Fuel-Vapor/O/N Flames", $J$ Propulsion Power, 16(3): 513-522, 2000, doi: 10.2514/2.5598.

62. Huang, Y., Sung, C.J., and Eng, J.A., "Laminar Flame Speeds of Primary Reference Fuels and Reformer Gas Mixtures", Combust. Flame. 139: 239-251, 2004, doi: 10.1016/j.combustflame.2004.08.011.

63. Kwon, K., Freeh, J.E., Sung, C.J., and Huang, Y., "Laminar Flame Speeds of Preheated Iso-octane $/ \mathrm{O}_{2} / \mathrm{N}_{2}$ and $\mathrm{n}$ heptane $/ \mathrm{O}_{2} / \mathrm{N}_{2}$ Mixtures", J. Propulsion Power. 23(2): 428-436, 2007, doi: $10.2514 / 1.24391$.

64. Van Lipzig, J.P.J., Nilsson, E.J.K., de Goey, L.P.H., and Konnov, A.A., "Laminar Burning Velocities of n-heptane, Isooctane, Ethanol and Their Binary and Tertiary Mixtures", Fuel. 90: 2773-2781, 2011, doi: 10.1016/j.fuel.2011.04.029.

65. Dirrenberger, P., Glaude, P.A., Bounaceur, R., Le Gall, H. et al. "Laminar Burning Velocities of Gasolines with Addition of Ethanol", Fuel. 115: 162-169, 2014, doi: 10.1016/j.fuel.2013.07.015.

66. Broatch, A., Margot, X., Novella, R., and Gomez-Soriano, J., "Combustion Noise Analysis of Partially Premixed Combustion Concept Using Gasoline Fuel in a 2-stroke Engine", Energy. 107: 612-624, 2016, doi:10.1016/j.energy.2016.04.045.

67. Kalghatgi, G. T., Golombok, M., and Snowdon, P., "Fuel Effects on Knock, Heat Release and "CARS" Temperatures in a Spark Ignition Engine," Combust Sci Technol. 110-111(1): 209-228, 1995, doi: 10.1080/00102209508951924.

68. Yates, A.D.B., Swarts, A., and Vilijoen, C.L., "Correlating Auto-ignition Delays and Knock-Limited Spark-Advance Data for Different Types of Fuel", SAE Paper No. 2005-01-2083, 2005, doi: 10.4271/2005-01-2083.

69. Foong, T.M., Brear, M., Morganti, K., Silva, G. et al., "Modeling End-gas Auto-ignition of Ethanol/Gasoline Surrogate Blends in the Cooperative Fuel Research Engine", Energy Fuels. 31(3): 2378-2389, 2017, doi: 10.1021/acs.energyfuels.6b02380.

70. Scarcelli, R. and Zhang, A., "Advances in Modeling Ignition Processes to Enable High-Efficiency SI Combustion", AEC Program Review Meeting, Southfield, MI, USA, 2017.

\section{Contact Information}

Pinaki Pal, Ph.D.

Postdoctoral Appointee

Argonne National Laboratory

9700 S. Cass Avenue

Lemont, IL- 60439

pal@anl.gov

Page 11 of 12 


\section{Acknowledgments}

The submitted manuscript has been created by UChicago Argonne, LLC, Operator of Argonne National Laboratory (Argonne). Argonne, a U.S. Department of Energy Office of Science laboratory, is operated under Contract No. DEAC02-06CH11357. The U.S. Government retains for itself, and others acting on its behalf, a paidup nonexclusive, irrevocable worldwide license in said article to reproduce, prepare derivative works, distribute copies to the public, and perform publicly and display publicly, by or on behalf of the Government. This research was partially funded by DOE's Office of Vehicle Technologies and Office of Energy Efficiency and Renewable Energy under Contract No. DE-AC02-06CH11357. The authors wish to thank Gurpreet Singh, Kevin Stork, and Leo Breton, program managers at DOE, for their support. This research was conducted as part of the Co-Optimization of Fuels \& Engines (CoOptima) project sponsored by the U.S. Department of Energy (DOE) Office of Energy Efficiency and Renewable Energy (EERE), Bioenergy Technologies and Vehicle Technologies Offices.

The authors would also like to acknowledge the HPC center at the National Renewable Energy Laboratory for computing time on the Peregrine cluster as well as the Laboratory Computing Resource Center at Argonne National Laboratory for computing time on the Blues cluster that were used in this research. Lastly, the authors would like to acknowledge Dr. R. Torelli, Dr. A.A. Moiz and Dr. P. Kundu of Argonne National Laboratory for their generous help in creating the surface mesh of the CFR engine from the X-ray scan. 